\title{
Interpretações da colônia. Leitura das contribuições de Nelson Werneck Sodré e Alberto Passos Guimarães ${ }^{1}$
}

\author{
Carlos Alberto Cordovano Vieira?
}

\section{INTRODUÇão}

A presente comunicação pretende discutir as intepretações da colônia apresentadas nas obras de Nelson Werneck Sodré e Alberto Passos Guimarães com o propósito, não de esgotar o tema, mas de sistematizar seus traços mais essenciais, qualificando determinadas interpretações e críticas. O debate sobre o caráter da sociedade colonial está profundamente vinculado ao debate mais geral sobre os dilemas postos à sociedade brasileira em momento histórico subseqüente. E, admitindo a importância da herança de contribuições das grandes interpretações do Brasil forjadas pelo menos desde o ensaísmo dos anos trinta, senão antes, que, naturalmente, buscaram compreender, por diferentes caminhos, os dilemas estruturais da sociedade brasileira, podemos reconhecer a importância, sobretudo na atualidade, da releitura dessas obras, ou de

1. 0 presente trabalho foi elaborado a partir das discussões apresentadas na dissertação de mestrado do autor, apresentada no Programa de História Econômica do Instituto de Economia da Universidade Estadual de Campinas, IE-UNICAMP, em 2004, com o título Interpretações da colônia: leitura do debate brasileiro de inspiração marxista; e na comunicação apresentada pelo autor ao VI Congresso da Associação Brasileira de Pesquisadores em História Econômica, ABPHE, em 2005, a ser publicada em seus Anais, com título Interpretações da colônia e transição do feudalismo ao capitalismo. Registramos a contribuição dos professores Plínio Soares de Arruda Sampaio Júnior, Lígia Osório Silva e Flávio Azevedo Marques de Saes.

2. Mestre pelo Programa de Desenvolvimento Econômico e História Econômica do Instituto de Economia da Universidade Estadual de Campinas, IE - UNICAMP e Professor das Faculdades Santa Marcelina, Fundação Escola de Comércio Álvares Penteado e Fundação Santo André. Endereço eletrônico: cordovanovieira@yahoo.com.br. 
alguns de seus aspectos fundamentais. Não abordaremos aqui, entretanto, o sentido político do debate, já abordado em outro trabalho ${ }^{3}$.

A chave que orienta a presente leitura aponta para o reconhecimento, como questão fundamental, da preocupação de definir a estrutura e a dinâmica subjacente ao movimento da sociedade colonial. Trata-se, pois, de uma sociedade inscrita como extensão do espaço europeu, nos quadros da expansão política, econômica e cultural do mercantilismo, que, ao mesmo tempo, apresenta uma conformação social e econômica particular; um organismo estruturalmente vinculado à teia do mercado mundial, no movimento de expansão européia, edificado, porém, sobre relações de produção específicas. Assim, impõe-se, como problema fundamental, a necessidade de compreensão de forma integrada desta dupla dimensão, como momento decisivo para a apreensão da totalidade que circunscreve o objeto, a saber, a colônia. Naturalmente, o debate perpassa diversas gradações entre interpretações polares que privilegiam como elemento fundamental da estrutura os nexos mercantis sistêmicos ou as relações de produção escravistas e senhoriais.

Em grandes linhas, estes autores se dedicaram a desenredar a difícil combinatória entre a forma de inserção na economia internacional das terras colonizadas pelos portugueses na América e os aspectos concretos assumidos pela sociedade que se monta nessa área no período que vai do século XVI ao século XIX, tarefa para qual era indispensável apurar as causas da adoção da escravidão colonial e suas relações com o desenvolvimento do capitalismo na Europa. ${ }^{4}$

Desse modo, é possivel delinear a posição das interpretações da colônia de Werneck Sodré e Alberto Passos nos quadros do debate brasileiro e, em particular, do debate referido ao materialismo histórico. Com efeito, pode-se sugerir que uma leitura crítica das referidas interpretações, o reconhecimento de sua complexidade e de seus limites, talvez explicite os problemas postos às tentativas de apreensão da estrutura e dinâmica da sociedade colonial. Pois, não obstante diferenças decisivas, as interpretações da

3. Carlos Alberto Cordovano Vieira. Interpretações da colônia: leitura do debate brasileiro de inspiração marxista. Tese de Mestrado, IE-UNICAMP, Campinas, 2004.

4. Lígia Osório Silva: "Feudalismo, capital mercantil, colonização". In: João Q̨uartim de Moraes e Marcos Del Roio (orgs.). História do marxismo no Brasil, 4 vols. Campinas, Editora da UNICAMP, 1998, vol. IV, p. 18.

32 Interpretações da colônia. Leitura das contribuições de Nelson Werneck Sodré e Alberto Passos Guimarães 
colônia de Werneck Sodré e Alberto Passos apontam no sentido da necessidade de articulação da dimensão mercantil constitutiva da exploração colonial com as formas edificadas no interior do espaço colonial, em particular, suas relações de produção ou formas de propriedade. Trata-se, na verdade, de uma tendência à justaposição de duas dinâmicas distintas determinadas, de um lado, pelos nexos de exploração mercantil como suporte do processo de acumulação primitiva de capital, e, de outro, pelas relações de produção escravistas ou servis, ou formas de propriedade ditas feudais. A centralidade conferida às relações de produção na definição e caracterização do modo de produção conduziu, no movimento de justaposição da dupla dimensão da sociedade colonial, a formulações sobre a vigência, na colônia, de manifestações concretas de modos de produção universais, ou seja, do modo de produção escravista, do modo de produção feudal ou das formas híbridas.

No debate marxista, a posição das contribuições de Werneck Sodré e Alberto Passos define-se, quase imediatamente, a partir do diálgo e do contraponto que estabelecem em relação à interpretação de Caio Prado. Pois o sentido da colonização, como problema que perpassa o conjunto da obra de Caio Prado, remete à centralidade dos nexos mercantis e, enfim, à profunda extroversão que marca, em todos os seus aspectos, a sociedade colonial. Uma sociedade compreendida como extensão do domínio europeu em processo de diferenciação, como organismo complementar e reflexo em relação ao pólo metropolitano, sem força própria, cujas estruturas e dinamismos particulares adquirem sentido somente quando remetidos ao movimento sistêmico da expansão mercantilista, às necessidades da exploração comercial empreendida pelo capital mercantil. Uma sociedade cuja base material não constitui a infra-estrutura de seu substrato humano; e cujos nexos da vida social, sendo nexos primários, não constituem propriamente uma superestrutura. Enfim, uma sociedade em formação, caracterizada pela precariedade e instabilidade ao nível da vida material e pela anomia social. Portanto, trata-se do movimento de apreensão da totalidade orgânica em que se inscreve o objeto, a sociedade colonial, que escapa à concepção de um modo de produção imediatamente definido pelas relações sociais de produção estabelecidas internamente ${ }^{5}$.

No momento seguinte, recompõe-se o debate referido ao materialismo histórico, sobretudo, nas contribuições de Fernando Novais e Jacob Gorender. O problema da dupla dimensão da sociedade colonial toma corpo, então, na questão da apropriação do

5. Caio Prado Júnior. Formação do Brasil contemporâneo - colônia. 11ạ. edição. São Paulo, Brasiliense, 1971.

Marxismo e ciências humanas

cadernos cemarx, nํㅜ - $2006 \quad 33$ 
excedente e nas possibilidades de internalização da acumulação. Fernando Novais, na senda das interpretações sistêmicas, inscreve o sistema colonial no quadro da transiç̧ão do feudalismo ao capitalismo, como peça fundamental da acumulação primitiva de capital. Com isso, explicitamente retira o sentido da idéia de estruturas especificamente internas ao espaço colonial que não sejam, na verdade, internas ao sistema tomado em seu conjunto, ou seja, à estrutura do movimento de formação do capitalismo. Assim, articulam-se organicamente expansão mercantilista e expansão das monarquias absolutistas, formação do capitalismo e formação do Estados nacionais, e nesse quadro os processos de acumulação primitiva de capital, entre os quais, o sistema colonial. Vale dizer, trata-se de uma acumulação interna ao sistema; da apropriação de riqueza, pela violência, por exemplo, da exploração colonial, em favor de uma burguesia mercantil ${ }^{6}$.

Jacob Gorender e Ciro Cardoso aprofundam o propósito de conferir centralidade à dimensão das relações internas ao espaço colonial, elaborando a economia política de um modo de produção especificamente colonial, regido por leis próprias. Trata-se, pois, de um modo de produção dependente, constituído por uma aritculação de condicionantes internos e externos subordinada à dimensão das contradições intrínsecas a essas relações específicas de dominação escravista. O vetor das estruturas internas afirmase, então, sobre o vetor das conexões sistêmicas, porquanto a dinâmica da sociedade colonial, sua potencialidade e seus limites são dados pelas contradições constitutivas do modo de produção escravista colonial. E, no entanto, o referido modo de produção somente pode existir como modo de produção dependente. A problemática resulta na admissão da possibilidade de acumulação interna ao escravismo colonial e portanto à própria sociedade colonial, com o que será relativizado o peso da exploração mercantil na conformação da colônia e, no limite, na própria formação do capitalismo?

O propósito da presente leitura é sistematizar as contribuições de Werneck Sodré e Alberto Passos, qualificando certas críticas recorrentes. Pretende sugerir, somente, que a consideração de elementos dinâmicos internos, e mesmo a idéia de feudalismo, ainda que a expressão abarque uma vasta gama de significados, esteve, em muitos casos, sob distintas orientações ideológicas, presentes no debate brasileiro e, portanto, deve ser situada nesse

6. Fernando Novais: “Caio Prado Jr. na historiografia brasileira”. In: Reginaldo Moraes et alli (orgs.). Inteligência Brasileira. São Paulo, Brasiliense, 1986 e Fernando Novais. Portugal e Brasil na crise do antigo sistema colonial (1777-1808). 6a. edição. São Paulo, Hucitec, 1995.

7. Ciro Flamarion Cardoso et alli. Modos de producción em América Latina. 2a. edição. Córdoba, Passadoy Presente, 1974 e Jacob Gorender. O escravismo colonial. 6ª edição. São Paulo, Ática, 1992.

34 Interpretações da colônia. Leitura das contribuições de Nelson Werneck Sodré e Alberto Passos Guimarães 
contexto. Com isso, pretende reconhecer a existência de elementos empíricos que, não podendo, naturalmente, oferecer respostas definitivas aos problemas, por outro lado, não poderiam falsear de modo imediato aquelas teses. Nesse sentido, pensamos ser insuficiente a crítica aos autores em tela que reduz a questão aos problemas, muito recorrentes no marxismo da época, de transposição mecânica de modelos abstratos. O ponto crítico parece ser a dificuldade, nos marcos dessas interpretações, de articular organicamente a dupla dimensão subjacente à sociedade colonial, provavelmente derivada de concepções rígidas sobre a categoria modo de produção. Com isso, parece surgir uma dificuldade particular para a apreensão do sentido histórico concreto dessas sociedades.

\section{ESCRAVISMO, FEUDALISMO E FORMAS HÍBRIDAS}

Considerando as múltiplas possibilidades de interpretação da colônia derivadas da complexidade da sociedade colonial, ou seja, de referida dupla determinação, externa e interna, da vida colonial, pode-se compreender a afirmação, no pensamento brasileiro, de uma tendência a delimitar como marco estrutural explicativo a estrutura interna ao espaço da colônia, em particular, a grande lavoura. As relações de arbítrio que caracterizam a dominação dos senhores proprietários sobre uma massa de escravos e daquela gente que vegetava na órbita do latifúndio. Nesse universo, ressalta-se o predomínio do latifúndio sobre a vida colonial, que asfixia qualquer forma de existência estabelecida fora de seus domínios. Define-se a desagregação e desestruturação do espaço colonial, a ausência de poder estatal, sobre o que se edificam as relações de dependência em relação ao poder privado e absoluto dos senhores. Assim, um conjunto de interpetações da colônia, que derivam de variadas matrizes historiográficas, teóricas e ideológicas, verão no latifúndio o único organismo capaz de estruturar, com mais ou menos organicidade, as bases sociais e econômicas da vida colonial ${ }^{8}$.

A própria idéia de feudalismo, que, de resto, expressa conceitos essencialmente distintos, aparece numa vasta gama de obras sobre a colônia. Seja para definir os termos de uma fragmentação do poder, que revela o poder particularista dos senhores, seja para definir uma economia fechada, na base de organismos relativamente autônomos em meio à precariedade do mercado interno, seja para definir uma categoria de modo de produção referida a relações sociais de produção, a imagem de um latifúndio feudal ou semifeudal aparece, de formas mais ou menos explícitas. Duas referências basila-

8. José Roberto do Amaral Lapa (org.). Modos de produção e realidade brasileira. Petrópolis, Vozes, 1980. 
res da reflexão brasileira de orientação conservadora, e mesmo autoritária, situam os nexos fundamentais da vida colonial nos marcos do latifúndio, compreendido como universo fechado sobre si mesmo. Oliveira Vianna, por exemplo, havia demonstrado o caráter disperso e centrífugo da sociedade colonial, sobretudo no que respeita à ausência de um poder político centralizador, atribuindo ao grande domínio rural compreendido em seus múltiplos aspectos, e sobretudo no aspecto político (que ele denomina complexo do feudo), papel de única força de aglutinação política e único espaço de "solidariedade social".

(...) o clã rural - o clã fazendeiro, a porção mais importante talvez do nosso 'complexo feudo' - é a única forma de solidariedade do povo-massa dos campos que a nossa nobreza territorial conseguiu organizar. Não foi esta, porém, a única forma de solidariedade social que o grande domínio organizou. O clã feudal é a organização da solidariedade do povo-massa - da plebe dos campos; mas, para a elite rural, o grande domínio organizou uma outra espécie de solidariedade social: o clã parental. O clã parental é uma organização aristocrática. É uma espécie de Ordem da Cavalaria das grandes famílias dominicais. Foi enorme a sua influência no Período Colonial e, ainda maior, no Período Imperial e na República. ${ }^{9}$

Gilberto Freyre, outro exemplo, demonstrou também a centralidade do grande domínio e em particular da família patriarcal, em perspectiva sociológica ${ }^{10}$.

O mesmo sentido revela-se nas referências feitas por Werneck Sodré ao universo

9. Oliveira Vianna. Instituições políticas brasileiras, 2 vols., Niterói, EDUFF, 1987, vol. I, p. 181-182.

10. “A casa-grande, completada pela senzala, representa todo um sistema econômico, social, político: de produção (a monocultura latifundiária); de trabalho (a escravidão); de transporte (o carro de boi, o bangüê, a rede, o cavalo); de religião (o catolicismo de família, com capelão subordinado ao pater familias, culto dos mortos etc.); de vida sexual e de família (o patriarcalismo polígamo); de higiene do corpo e da casa ('tigre', a touceira de bananeira, o banho de rio, o banho de gamela, o banho de assento, o lava-pés); de política (o compadrismo). Foi ainda fortaleza, banco, cemitério, hospedaria, escola, santa casa de misericórdia amparando os velhos e as viúvas, recolhendo órfãos. (...) A casa-grande venceu no Brasil a Igreja, nos impulsos que esta em princípio manifestou para ser dona da terra. Vencido o jesuíta, o senhor de engenho ficou dominando a colônia quase sozinho. 0 verdadeiro dono do Brasil. Mais do que os vice-reis e os bispos. A força concentrou-se nas mãos dos senhores rurais. Donos das terras. Donos dos homens. Donos das mulheres. Suas casas representam esse imenso poderio feudal. 'Feias e fortes'." Gilberto Freyre. Casa-grande \& senzala - Introdução à história da sociedade patriarcal no Brasil. 41 ạ edição. São Paulo, Record, 2000, p. 49-50.

36 Interpretações da colônia. Leitura das contribuições de Nelson Werneck Sodré e Alberto Passos Guimarães 
da literatura brasileira, objeto de seus primeiros estudos ${ }^{11}$. Portanto, parece ser necessária uma releitura da interpretação de Werneck Sodré, na intenção de qualificar um conjunto de críticas, há muito sedimentadas. Pois quando se observa esse diálogo entre diversas tendências de interpretação da colônia, edificadas sobre diferentes matrizes, pode-se reconsiderar a crítica às tendências de aplicação mecânica de modelos préestabelecidos em nível abstrato. Se essas contribuições não são simples reproduções automáticas, correias de transmissão de idéias estranhas à realidade concreta, e se esses historiadores marxistas não são simples agentes passivos de uma dominação ideológica, a questão seria reorientada no sentido de indagar a base sobre a qual constituem-se aqueles diálogos. Por exemplo, indagar a respeito do possível diálogo entre teses de orientação marxista e cepalina, quanto ao confronto entre o novo e o arcaico na sociedade brasileira. Assim, sem a pretensão de tomar o debate em seu conjunto, sugerimos apenas um caminho para uma releitura crítica, mais atenta às tendências ao dualismo do que ao esquematismo. Com efeito, em resposta aos críticos, Werneck Sodré procurava sustentar a base essencialmente empírica de suas formulações. Isso remete a uma leitura crítica que considere a relação entre a apreensão da realidade e a formulação conceitual, o que remete ao modo como essa interpretação propõe incorporar as categorias marxistas, no contexto do marxismo da época ${ }^{12}$.

11. “Mesmo em manifestações artísticas - peças de teatro, romances, contos, crônicas - as relações feudais apareceram, de velhos tempos. Elementos comuns à temática medieval, conseqüentemente, aparecem na ficção brasileira: a mulher que se disfarça em homem para combater ou exercer vingança, os amores contrariados pela rivalidade familiar, as gestas de bandos armados varrendo os sertões. No fundo do amplíssimo painel das guerrilhas narradas em Grande Sertão: Veredas está o latifúndio feudal, em seu esplendor." Nelson Werneck Sodré: “Modos de produção no Brasil”. In: José Roberto do Amaral Lapa (org.), Modos de produção e realidade brasileira. Petrópolis, Vozes, 1980, p. 147.

12. “Assim, não apenas os modos de produção se apresentam, aqui, como formas particulares, que os distinguem do modelo conceitual, como não poderia deixar de ser, mas também do modelo empírico do Ocidente europeu; também são diferentes as formas de passagem de um a outro modo de produção, de uma a outra formação social. (...) Claro está que não se nega, de plano, a possibilidade de passagem de um modo a outro de produção sem intermediação da seqüência clássica. (...) Mas o fato é que, no Brasil, no nosso modo de ver, tanto houve escravismo e passagem ao feudalismo, quanto feudalismo e passagem ao capitalismo. Esta seqüência, por assim dizer normal, porque acompanha o modelo conceitual e o esquema stalinista, decorre da análise do particular brasileiro e não da simples adoção de uma fórmula como se fora universal e obrigatória." Nelson Werneck Sodré. Capitalismo e revolução burguesa no Brasil. Belo Horizonte, Oficina de Livros, 1990, p. 24-25. Os trabalhos de Paulo Cunha oferecem a possibilidade de identificar concretamente, na biografia do autor, os momentos da observação empírica, sobretudo em suas viagens pelo Brasil. Paulo Ribeiro da Cunha. Um olhar à esquerda: a utopia tenentista na construção do pensamento marxista de Nelson Werneck Sodré. São Paulo, FAPESP, 2002.

Marxismo e ciências humanas cadernos cemarx, n-3-2006 37 
Uma apreciação das formas de reprodução da vida na colônia não poderia concluir pela presença de algum modo de produção conformado e desenvolvido em épocas ou espaços remotos, em diversos contextos históricos, sem a abstração do conteúdo concreto que constitui a sociedade colonial, em quase tudo diversas de outras tantas formas socioeconômicas. Com efeito, delimitar no interior daquela sociedade edificada pela colonização portuguesa no continente americano, na época dos descobrimentos, um modo de produção escravista ou feudal significa situar, no âmbito de uma mesma definição, formações sociais diversas, em termos de seu sentido histórico concreto. Vale dizer, em algum nível de realidade, esses trópicos identificam-se com sociedades desenvolvidas no mundo antigo ou na cristandade medieval. Por certo, seria em certa medida anacrônico um juízo dessas formulações, sem levar em conta serem tais concepções correntes no marxismo daqueles tempos. Pois o próprio debate sobre a transição entre Maurice Dobb e Paul Sweezy revela, em algumas passagens, idéias sobre feudalismos, além das fronteiras da Europa cristã; ou então, o conhecido debate sobre o modo de produção asiático ${ }^{13}$.

Importa observar que a assimilação de totalidades históricas essencialmente distintas a um mesmo modo de produção sugere que o arcabouço conceitual tenha sido elaborado em elevado nível de abstração. Ou seja, sugere que a categoria modo produção, assim compreendida, possa conduzir à abstração de dimensões essenciais para a compreensão do movimento histórico concreto. No caso das interpretações da colônia, a assimilação da sociedade colonial a modos de produção ditos universais poderia conduzir à abstração do próprio caráter colonial daquela sociedade, em favor de relações de produção constituídas internamente. Ou seja, poderia implicar no deslocamento de nexos internos de suas articulações sistêmicas, em favor da idéia de uma relativa "autonomia" do espaço colonial.

No entanto, a dimensão das articulações sistêmicas seria ainda peça constitutiva nas formulações do modo de produção colonial, de modo mais ou menos central. Por certo,

13. Houve mesmo uma tendência de classificar como feudal qualquer formação mais ou menos situada entre o escravismo e o capitalismo, independente de suas caracterizações específicas. Eric Hobsbawm, em sua introdução a Formações econômicas pré-capitalistas, contextualiza essa ampliação no raio das formações feudais, referindo-se à tendência geral que "conduziu a uma revisão formal da lista das formações econômicosociais de Marx ao omitir o 'modo asiático', limitar o campo do 'antigo' mas, correspondentemente, ampliando o 'feudal'". Eric Hobsbawm: "Introdução". In: Karl Marx. Formações econômicas pré-capitalistas, trad. João Maia. 2a edição. Rio de Janeiro, Paz e Terra, 1977, p. 60.

38 Interpretações da colônia. Leitura das contribuições de Nelson Werneck Sodré e Alberto Passos Guimarães 
seria mais central nas interpretações de Werneck Sodré, cujos nexos fundamentais não recaem sobre uma dinâmica interna ao espaço da colonização, referida ao funcionamento de um modo de produção colonial específico, muito embora procurem quase sempre caracterizá-lo. Concretamente, procurou-se compreender a dinâmica da sociedade colonial sob o prisma de distintas dimensões que pudessem expressar um nível de realidade referido à exploração mercantil e outro ao modo de produção americano. Com isso, a sociedade colonial seria compreendida no quadro do desenvolvimento da economia mercantil, como organismo social conformado pela dinâmica do capital mercantil, e, portanto, caracterizado por sua profunda extroversão. Resguarda-se, pois, seu caráter essencialmente complementar e reflexo, e sua decorrente instabilidade, conferindo centralidade aos mecanismos da exploração mercantil, definidos pelo correspondente fluxo desacumulador ${ }^{14}$. Em paralelo, procura-se caracterizar as relações de produção estabele-

14. Nesse ponto, cumpre observar o diálogo com as interpretações sistêmicas. Werneck Sodré, em Formação histórica do Brasil, utiliza por mais de uma vez a expressão finalidade da colonização, o que remete quase imediatamente ao sentido da colonização, de Caio Prado (p. 70 e segs.). Em Introdução à revolução brasileira, faria citação explícita: “Não será a simples feitoria comercial, que jávimos irrealizável na América. Mas conservará, no entanto, um acentuado caráter mercantil; será a empresa do colono branco, que reúne à natureza pródiga em recursos aproveitáveis para a produção de gêneros de grande valor comercial, o trabalho recrutado entre raças inferiores que domina: indígenas ou negros africanos importados. Há um ajustamento entre os tradicionais objetivos mercantis que assinalam o início da expansão ultramarina da Europa, e que são conservados, e as novas condições em que se realizará a empresa. Aqueles objetivos, que vemos passar para o segundo plano nas colônias temperadas, se manterão aqui, e marcarão profundamente a feição das colônias do nosso tipo, ditando-Ihes o destino. No seu conjunto, e vista no plano mundial e internacional, a colonização dos trópicos toma o aspecto de uma vasta empresa comercial, mais completa que a antiga feitoria, mas sempre com o mesmo caráter que ela, destinada a explorar os recursos naturais de um território virgem em proveito do comércio europeu. É este o verdadeiro sentido da colonização tropical, de que o Brasil é uma das resultantes; e ele explicará os elementos fundamentais, tanto no econômico como no social, da formação e evolução histórica dos trópicos americanos". Caio Prado Júnior. Formação do Brasil contemporâneo. 11 ª edição. São Paulo, Brasiliense, 1971, p. 31, apud Nelson Werneck Sodré. Introduçãoà revolução brasileira. 4a edição. São Paulo, Ciências Humanas, 1978, p. 67. Em Formação histórica do Brasil, explicita em suas próprias palavras: “No desenvolvimento da produção colonial brasileira verifica-se, muito cedo, uma enorme capacidade de acumulação. Acontece, porém, que tal acumulação não se opera na área da produção mas na área da circulação, o que decorre do fato fundamental de que a produção depende da circulação, na fase do capital comercial, e do fato conseqüente de que a estrutura açucareira de produção é uma empresa do capital comercial montada para servi-lo. É a circulação, assim, que comanda a produção. Existe um fluxo constante, uma transferência constante de renda da área da produção para a da circulação. Esta não é uma característica apenas do caso brasileiro: toda economia colonial corresponde a uma transferência de renda para o exterior". Nelson Werneck Sodré. Formação histórica do Brasil. 9ạ edição. Rio de Janeiro, Civilização Brasileira, 1976, p. 85. 
cidas no interior da sociedade colonial, definidas como escravistas ou feudais, sobre as quais elabora-se uma concepção do modo de produção edificado no espaço colonial.

Claro está que, visto o problema na dimensão universal, apresenta-se de determinada maneira; visto na dimensão americana, apresenta-se de outra maneira. Assim, na dimensão universal trata-se de processo de acumulação primitiva, quando eram vigentes as formas pré-capitalistas do capital - no caso, o capital comercial. Mas, na dimensão continental americana - sul-americana, no caso -, trata-se de escravismo puro e simples. ${ }^{15}$

"(...) escravismo puro e simples", na opinião de Werneck Sodré. No entanto, certos traços viriam conferir alguma particularidade ao escravismo moderno do espaço colonial diante das formas do escravismo antigo, do dito modelo clássico. Primeiro porque quando se edifica no tempo dos descobrimentos, aparece "deslocado" na seqüência progressiva do referido modelo clássico, como modo de produção historicamente superado e em algum nível de realidade descompassado em relação ao percurso histórico da transição do feudalismo ao capitalismo europeu. Configura-se, pois, como manifestação da heterocronia, do desenvolvimento desigual. Mas também por constituir-se não como resultado histórico do desenvolvimento progressivo das comunidades primitivas indígenas, não como etapa histórica subseqüente ao comunismo primitivo, mas como realidade social transplantada. Essas duas considerações traduzem desde logo a necessidade de compreender o escravismo do espaço colonial e o próprio tráfico negreiro, em sua especificidade, no quadro histórico da colonização moderna, das relações sistêmicas constitutivas da exploração mercantil ${ }^{16}$.

15. Nelson Werneck Sodré. Capitalismo e revolução burguesa no Brasil. Belo Horizonte, Oficina dos Livros, 1990, p. 12. 16. Werneck Sodré observa com certa ênfase a posição do tráfico negreiro na dinâmica da exploração mercantil como negócio dos mais rentáveis, aproximando-se, em alguma medida, da construção posterior de Fernando Novais. No entanto, não chega a situar no tráfico negreiro as explicações para a própria introdução da escravidão do africano: “Estabelecida em tais bases, a colonização confere extraordinário impulso a uma das áreas mais ativas da fase mercantil, a do tráfico negreiro. 0 problema fundamental da empresa ultramarina estava no fato de que não funcionaria de início como mercado: tinha poucas exigências, necessitava pouco de mercadorias européias, sua demanda era reduzidíssima. Desde logo, entretanto, aparecendo como estrutura escravista, vai representar um mercado para esse produto especial que é o escravo africano, o mais valioso do tempo. A ajuda que a empresa ultramarina empresta ao desenvolvimento do capital comercial não se limita, assim, ao que produz - o açúcar-, mas ao que consome- oescravo. Oaparecimento daárea escravista americana, no séculoXVI,é, desse modo, a poderosa alavanca em que o capital comercial se apóia para passar a uma nova etapa em seu desenvolvimento". Nelson Werneck Sodré. Formação histórica do Brasil. 9a edição. Rio de Janeiro, Civilização Brasileira, 1976, p. 72-73.

40 Interpretações da colônia. Leitura das contribuições de Nelson Werneck Sodré e Alberto Passos Guimarães 
Em nível mais geral, somente o caráter colonial poderia explicar a persistência desse organismo social edificado sobre forças produtivas menos desenvolvidas, a permanência da forma escravista na época de declínio do feudalismo. Pois se trata de uma organização econômica isolada internamente pela precariedade da divisão do trabalho, do mercado interno, e, externamente, pelo exclusivo metropolitano. Portanto, desde logo, esse escravismo, constituído como realidade heterocrônica e transplantada, somente poderia edificar-se plenamente porque circunscrito à condição colonial. Nesse sentido, o escravismo deveria ser compreendido à luz da própria vida material da sociedade colonial, caracterizada por sua profunda extroversão: uma estrutura econômica subordinada ao mercado mundial, complementar e reflexa à dinâmica européia, orientada segundo as necessidades da exploração mercantil, que não se constitui como fundamento material da reprodução de seu substrato humano. Uma vida material marcada pela precariedade e instabilidade estrutural de uma dinâmica predatória de seu substrato natural e alheia ao seu substrato humano que realiza tão somente o mínimo necessário ao proveito do negócio mercantil ${ }^{17}$. Mesmo no plano das relações de produção, esse escravismo adquire feição particular. Marx demonstrou que os vínculos com o mercado mundial, no contexto da colonização moderna, potencializam a extração do sobretrabalho, tornando as relações de dominação escravistas das colônias mais violentas, à diferença das formas de dominação orientadas para a satisfação das necessidades imediatas. No entanto, isso se torna mais grave quando atuam os efeitos do tráfico negreiro, que atenuam os efeitos antieconômicos da superexploração e destruição da força de trabalho do escravo, vale dizer, da esterilização de capital previamente invertido.

17. “Longe, e muito longe, de estabelecer as bases para uma exploração dos recursos que a terra pode proporcionar, e em que fiquem associados os seus moradores ou filhos, a grande empresa comercial da colônia malbarata os seus elementos, relega a um nível baixíssimo a população, desmoraliza o trabalho, concentra os lucros em poucas mãos, está sempre longe de deixar vestígios duradouros, dissipa os recursos locais e apenas complementa a estrutura econômica européia. Trata-se, no caso dessa exploração, de uma tarefa predatória por excelência, de destruição dos recursos naturais, de esgotamento do solo, de derrubada da vegetação protetora - cega, imediatista, quase vesânica se não tivesse existido nela a lógica natural do tempo. Não se trata, a rigor, de agricultura, e nem pode ser comparada, de forma alguma, a qualquer atividade agrária normal. Enriquecendo a uns poucos, empobrece a todos os demais. Não deixa no meio em que se desenvolve os elementos substanciais de acumulação, que conferem estabilidade e possibilitam um desenvolvimento contínuo e ascensional. (...) A população não está de forma alguma associada ao sistema, mas profundamente divorciada dele." Nelson Werneck Sodré. Introdução à revolução brasileira. 4ạ edição. São Paulo, Ciências Humanas, 1978, p. 69-70.

Marxismo e ciências humanas

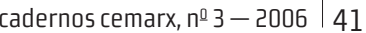


No entanto, a experiência do ouro traria modificações substanciais na vida colonial. Em fins do século XVII, a colônia está imersa em profunda crise, que remete ao acirramento da concorrência sobre a produção açucareira - sobretudo das colônias holandesas, mas também francesas e inglesas, melhor equipadas para a produção que a portuguesa - que viria minar o monopólio luso, fazendo declinar os preços do açúcar. Os outros espaços da colônia vegetavam naturalmente no baixo nível da subsistência. O milagre do ouro imprimiria um novo impulso à vida colonial. Primeiro, pelo vigoroso aumento da população colonial, do influxo de imigrantes europeus e escravos, e pela nova direção do povoamento, alcançando regiões centrais do território. Mas também por ser empresa de menor vulto, por exigir capitais de menor monta. Com isso, seriam abertas possibilidades para a pequena propriedade e para os empreendimentos dos homens livres e pobres, ao que se acrescenta certo abrandamento das relações escravistas e ascensão espiritual do escravo por conta da própria natureza da atividade. Trata-se de atividade especializada, o que viria a se refletir em impulso ao mercado interno, em maior entrelaçamento das regiões e mesmo nos progressos de uma vida urbana (até artística). Tais articulações implicariam numa pulverização dos lucros, desconsiderando o quinhão da coroa, e na formação de uma camada média, embrião remoto, para Werneck Sodré, de uma burguesia nacional. Esses desenvolvimentos, que culminariam nas insurreições, seriam expressões concretas do processo profundo de diferenciação, do qual emerge uma consciência nacional. Por essa razão, a mineração teria representado um profundo e irreversível abalo na ordem escravista ${ }^{18}$.

Mas considerando a interpretação em sua dupla dimensionalidade afirma-se, quase em paralelo à compreensão do escravismo em seu marco histórico concreto, como peça da acumulação primitiva, a definição do escravismo puro e simples, como modo de produção. Nessa perspectiva, o escravismo no espaço colonial seria manifestação concreta, expressão particular do fenômeno geral do modo de produção escravista vigente no mundo antigo. Não seria modo de produção específico, um escravismo colonial, diverso do escravismo antigo, com caracterização e funcionamento próprio, mas uma reedificação, descompassada no tempo e espaço do escravismo clássico. Por certo estaria implícito um conceito de modo de produção e um tratamento do mate-

18. Tais distinções entre mineração e grande propriedade açucareira seriam muito mais acentuadas por Werneck Sodré e menos por Caio Prado, que as compreende limitadas e situadas sobretudo em seu período de declínio.

42 Interpretações da colônia. Leitura das contribuições de Nelson Werneck Sodré e Alberto Passos Guimarães 
rialismo histórico, que nesse caso revelaria a centralidade atribuída à dimensão das relações de produção, mais propriamente ao regime de trabalho, como fundamento essencial e definidor da realidade social, em prejuízo da compreensão da totalidade das formas de reprodução da vida. No entanto, ao considerar o escravismo moderno em sua particularidade, o autor observaria, à diferença das formas do escravismo antigo, a ausência de correspondência entre infra-estrutura e superestrutura, o que atesta a separação dessas duas dimensões em nível mais estrutural da análise. Mais do que isso, reconheceria nesse escravismo moderno um modo de produção destituído de dinâmica autônoma. Na verdade, na análise, o regime de trabalho destaca-se do conjunto da vida social para definir-se como fundamento desse modo de produção escravista, antigo ou moderno - a dimensão das relações de produção desprende-se da totalidade ${ }^{19}$.

Como se sabe, o espaço escravista não esgota as formas socioeconômicas vigentes na sociedade colonial, restando vasta área subsidiária, muitas vezes vinculada às linhas de intercâmbio interno ou, noutros casos, organizadas como espaços relativamente autônomos, orientadas pela economia de subsistência. Ora, mesmo relativamente autônomos, vistos em certo nível de realidade, a própria conformação desses espaços socioeconômicos explica-se, em última instância, pela dinâmica sistêmica que rege a vida colonial, vale dizer, pela dinâmica da produção escravista integrada ao mercado mundial. Mas conformam, no plano da organização da vida socioeconômica, relações sociais diversas daquelas estabelecidas nos espaços escravistas. Werneck Sodré identificaria, pois, por toda a extensão do território colonial, um mosaico de formações socioeconômicas, a coexistência paralela, na forma metafórica do arquipélago, de distintos modos de produção, assim definindo o fenômeno da contemporaneidade do não-coetâneo. Em geral, esses espaços subsidiários, marginais à formação escravista, seriam caracterizados pelo autor, no nível das relações de produção, por formas feudais

19. Digno de nota o parágrafo de Werneck Sodré, em Introdução à revolução brasileira, que contraria sua tese central sobre o escravismo, reafirmada diversas vezes em outros trabalhos (inclusive em críticas diretas a Jacob Gorender): "Outro traço específico do quadro interno apresenta-se com o regime de trabalho escravo. Se atentarmos para o passado das áreas incluídas no campo geográfico da Revolução Comercial, verificamos como a introdução do elemento escravo complementou, em todas elas, a produção dos gêneros coloniais, mostrando a íntima associação que existiu entre os dois fatores. Trata-se, no caso, pois, de uma decorrência particular ao desenvolvimento do capital mercantil, nada tendo a ver, senão a semelhança, com o escravismo de época histórica mais recuada, quando o motivo de sua vigência foi inteiramente diverso". Nelson Werneck Sodré. Introdução à revolução brasileira. 4ª edição, São Paulo, Ciências Humanas, 1978, p. 68-69 (grifos nossos).

Marxismo e ciências humanas

cadernos cemarx, n-03-2006 43 
ou mistas, em definição cuja centralidade recairia principalmente sobre as formas de apropriação do excedente econômico e as relações de dependência social, que vinculam senhores e dominados. Assim, o povoamento do sertão teria estabelecido desde o início a reprodução de relações feudais. Trata-se da produção pastoril, circunvizinha e relativamente integrada à dinâmica da economia exportadora de açúcar, algodão ou ouro, autonomizada em certos casos, que conformaria modo de produção diverso, essencialmente feudal, coexistindo em paralelo à exploração escravista. Também a área vicentina assentada na pecuária, constituída como suporte da expansão do bandeirantismo, viria a ser, desde os primeiros tempos, o espaço da reprodução de relações feudais, estendendo-se pelas áreas sulinas e pelas circunvizinhanças da exploração mineira. A colonização dos missionários, demarcada pela economia coletora amazônica ou pela produção ervateira sulina, seria definida como outras áreas feudais (ou mistas), em particular caracterizadas pela produção para o intercâmbio de longa distância. Mas, em geral, esses espaços subsidiários tendiam a tornar-se relativamente autônomos, circunscrevendo-se nos marcos da economia natural, de subsistência.

Com efeito, essa caracterização dos espaços feudais não está limitada à esfera das relações de produção e estende-se a considerações sobre os elementos da superestrutura. Assim, o poder absoluto dos senhores proprietários, que absorviam as funções de justiça, de polícia, de administração e que faziam dos homens pobres seus dependentes diretos, sob a mística da fidelidade, seria expressões feudais. E também, contendas políticas, disputas pela propriedade, rivalidades entre famílias, e sua contraparte marginal no fanatismo ou no banditismo endêmico. No entanto, esses elementos aparecem na análise muito mais como manifestações exteriores de uma determinada realidade social do que como nexos sociais internamente articulados, compreendidos como faces de uma totalidade, capaz de explicá-la, aquela realidade, em suas conexões múltiplas e determinações recíprocas. Na realidade, expressam as formas peculiares assumidas por esse feudalismo tropical, pois que, observou o autor, o modo de produção feudal, em sua generalidade, jamais teria se apresentado sob uma "forma clássica". Mais ainda, a própria constituição dessas formas na colônia não corresponde ao movimento esquemático de concepções mais ortodoxas, porquanto não responde ao desenvolvimento progressivo e ascensional do escravismo, resultado de crescimento acumulativo, mas como uma regressão a níveis inferiores de desenvolvimento das forças produtivas, decorrência da desintegração da produção escravista. Quando tais relações não se estabeleceram no início da colonização, como forma necessária de adaptação às condições do meio, apareceram como resíduo do declínio da atividade exportadora e, portanto,

44 Interpretações da colônia. Leitura das contribuições de Nelson Werneck Sodré e Alberto Passos Guimarães 
como processo explicado pelos condicionantes estruturais da profunda instabilidade e do caráter itinerante da vida colonial, pela dinâmica sistêmica, em última instância. Novamente, como nas discussões sobre o escravismo, a determinação central do modo de produção recai sobre as relações de produção. Desprendem-se, em certa medida, de sua dinâmica mais concreta, vinculada ao movimento do núcleo exportador, e mesmo das condições estruturais e determinantes, em nível mais profundo de realidade, de sua própria tendência à relativa autonomização, quais sejam, o caráter absorvente e asfixiante da grande propriedade exportadora.

Por certo, essas teses sobre o feudalismo colonial estabeleceriam certos diálogos com outras interpretações, algumas exteriores ao âmbito do próprio marxismo, destacando-se certos pontos de confluência com visões de orientação cepalina, conformando o quadro intelectual que procurou compreender as relações entre um Brasil moderno e outro arcaico ${ }^{20}$. Na reflexão marxista exerceria influência particular na obra de Alberto Passos, cujas formulações recairiam de modo mais decisivo sobre o caráter feudal da colônia portuguesa, mesmo nas áreas conformadas pelo trabalho escravo. Trata-se ainda de preservar os nexos com a sociedade metropolitana, procurando desviar-se das idéias de um modo de produção especificamente colonial. Feudalismo, puro e simples. Mas essa formulação adquire traços singulares porquanto a sociedade colonial, à diferença da concepção anterior, é vista como extensão do espaço europeu na medida em que é conformada pela transferência das antigas instituições feudais vigentes na metrópole. Portugal apresenta-se como sociedade feudal em processo de transformação, no quadro dos desenvolvimentos do capital mercantil e de certa desintegração das antigas formas de propriedade. Nesse sentido, a colonização representa uma alternativa aos

20. Além do debate de inspiração marxista, outras considerações sobre um feudalismo colonial tomaram corpo, privilegiando um ou outro aspecto isolado da realidade. Em diálogo dos mais importantes naqueles tempos, a própria interpretação de Celso Furtado resvala no problema das relações arcaicas, fazendo-se em alguns casos referências explícitas a relações semifeudais, como em Dialética do desenvolvimento. Na verdade, foi profundamente inspirado por Henri Pirenne, que identificou feudalismo e ausência de intercâmbio: "Tanto a causa geral - o desaparecimento entre povos e culturas - quanto a causa econômica particular - a suspensão do comércio - que estão no fundamento da ordem feudal (...)". Celso Furtado. Economia colonial no Brasil nos séculos XVI e XVII. São Paulo, Hucitec, 2001, p. 22. Ora, neste caso, o espaço econômico relativamente autônomo orientado pela produção de subsistência, isolado sobretudo na área de economia pastoril, talvez pudesse ser definido como espaço feudal, segundo os termos da própria definição proposta. No entanto, referências de Celso Furtado explícitas ao feudalismo são mais esparsas e ocasionais, preservando em seu lugar a idéia do arcaico.

Marxismo e ciências humanas

cadernos cemarx, $\left.\mathrm{n}^{0} \mathbf{0}-2006\right) 45$ 
fidalgos, de reaverem o poder e o status de outros tempos, procurando estabelecer no novo continente vastos domínios territoriais, sobre os quais mandassem de modo inconteste e absoluto. Teriam, pois, os fidalgos lusitanos edificado, na colônia, uma estrutura tipicamente nobiliárquica, cujo nexo fundamental reside na forma de propriedade da terra, e à qual o próprio capital teria se submetido e amoldado.

No entanto, tal estrutura não reproduziria as mesmas formas vigentes na metrópole, pois, entendida como uma espécie de reação aristocrática aos efeitos transformadores do desenvolvimento mercantil, seria já expressão, em algum sentido, de um retrocesso histórico. Vale dizer, como estrutura tipicamente nobiliárquica, a sociedade colonial não incorpora os impulsos dinâmicos relativos aos desenvolvimentos do capital mercantil. Mais ainda, interagem condicionantes específicos, interferem circunstâncias concretas, que conferem caráter particular àquela sociedade nobiliárquica. A transferência das instituições ditas feudais não poderia realizar-se sem se curvar à força das circunstâncias, e desde logo, pela ausência de comunidades produtoras preestabelecidas sobre as quais pudessem instaurar seu domínio; não havia servos. Portanto, a reinvenção da escravidão explica-se, nessas interpretações, pelas necessidades de consolidação de uma sociedade nobiliárquica. Mas esse movimento não poderia realizar-se sem o concurso do capital e, portanto, o projeto aristocrático colonizador haveria de buscar aliança com burgueses, os homens de calidades, com os homens do dinheiro ${ }^{21}$. Trata-se, pois, de estrutura híbrida e tensa, em que se mescla o regime feudal de propriedade e o regime escravista de trabalho, conformando um modo de produção feudal-escravista.

Essa unidade produtora - o engenho - foi a célula da sociedade colonial, tornando-se, por muito tempo, a base econômica e social da vida brasileira. Era, como a sociedade que dele nascera, medularmente feudal. E se se quer dar uma designação mais precisa, tendo em conta os aspectos fundamentais de seu modo de produção, como feudal-escravista é que se deve definir tanto o engenho, como todo o período colonial da sociedade brasileira.22

Precisamente essas formas específicas de organização da sociedade colonial,

21. Observemos apenas que aqui haveria de estar implícita a consideração do tráfico como um negócio mercantil, mas parece não haver referência a respeito.

22. Alberto Passos Guimarães. Quatro séculos de latifúndio. 5ạ edição, Rio de Janeiro, Paz e Terra, 1981, p. 64 (grifos nossos).

46 Interpretações da colônia. Leitura das contribuições de Nelson Werneck Sodré e Alberto Passos Guimarães 
assim entendidas como retrocesso histórico, possibilitariam, segundo o autor, a consolidação do domínio da metrópole. Pois, tratando-se de sociedade essencialmente nobiliárquica, estruturada pela concentração e exploração dos vastos domínios rurais, como resistência à ascensão do capital mercantil e da manufatura, estariam limitadas as possibilidades de desenvolvimento da sociedade colonial. Como se as resistências feudais aos progressos do capitalismo fossem transferidas para o espaço colonial, as formas arcaicas seriam compatíveis com as formas mais modernas, e possibilitariam, de modo funcional, o domínio metropolitano. Assim articulam-se os dois espaços, mas as mazelas da colônia seriam atribuídas às resistências da aristocracia local, mais do que aos mecanismos da exploração mercantil.

Fora do engenho, nas fazendas circunvizinhas ou vicentinas e sulinas, outras formas de vida emergiam, sobretudo no vácuo legado pela impossibilidade do domínio absoluto dos senhores estender-se sobre terras tão vastas. Na vastidão das fazendas, onde o poder dos senhores quase desaparecia, surgia uma forma de vida mais livre, ou no caso do centro-sul, propriedades menores, mais acessíveis ao homem pobre; articulavam-se nexos de um mercado interno. Pois nessas regiões das fazendas surgiriam forças renovadoras mais democráticas, que animariam os movimentos pela independência e posteriormente a industrialização. Alberto Passos e Werneck Sodré chegam a conclusões tão parecidas quanto imagens refletidas, e naturalmente invertidas, num espelho: um vê a expressão mais nítida do feudalismo onde o outro vê escravismo mercantil; ao mesmo tempo, que vê o germe da reação ao feudalismo, onde o segundo vê a sedimentação das relações feudais!

Werneck Sodré criticou a idéia da transferência das instituições metropolitanas para a colônia, como uma forma parcial de compreender a realidade colonial, restrita à esfera das relações jurídicas. Mais ainda, considerando a impossibilidade de valorização econômica das novas terras pela simples posse, posto que lhe faltava o substrato do trabalho, confere justamente ao trabalho, a centralidade na montagem da colonização $0^{23}$.

23. “Não é difícil concluir que tal legislação trazia evidentes marcas feudais. Nem poderia ser de outra maneira, uma vez que a classe dominante em Portugal, na época, era a dos senhores feudais. Não há coincidência, também, no fato de que surgem novos pontos de vista quando estudiosos tomam em consideração os fatos e não as leis, regulamentos e cartas régias. A legislação foi uma coisa; a realidade foi outra coisa. Do exame da realidade - como a colonização aconteceu, e não como foi planejada - é que derivam as teses novas, de regime capitalista ou de regime escravista, declinando a de regime feudal. (...) Assim, a conclusão a que leva o exame da realidade é que o Brasil iniciou a sua existência colonial sob o modo de produção escravista." Nelson

Marxismo e ciências humanas

cadernos cemarx, nํ3-2006 47 
Trabalho comprado, por suposto. Por isso, faria recorrentes referências ao problema do investimento inicial da empresa da colonização, em tudo oneroso, reconstituindo de modo detalhado a história da presença do capital mercantil holandês na economia portuguesa, então em declínio. Nessa perspectiva, a terra, sem o investimento inicial e sem o escravo, seria de pouca valia e não despertaria qualquer interesse. Desse modo, a colonização estaria distante da transferência de uma classe aristocrática, para reproduzir nos trópicos suas formas arcaicas de vida. Seria obra de uns tantos fidalgos, oriundos de pequena nobreza, em geral, vinculados à Coroa por serviços prestados. Caio Prado, acrescentando observações sobre o caráter alodial pleno da propriedade, apresentara anteriormente a mesma linha de argumentação.

(...) no Brasil-Colônia, a simples propriedade da terra, independente dos meios de a explorar, do capital que a fecunda, nada significa. Nisto se distingue a nossa formação da Europa medieval saída da invasão dos bárbaros. Lá, encontraram os conquistadores descidos do Norte, uma população relativamente densa e estável que já se dedicava à agricultura como único meio de subsistência. O predomínio econômico e político dos senhores feudais resultou assim direta e unicamente da apropriação do solo, o que automaticamente gerava em relação a eles os laços de dependência dos primitivos ocupantes. Aqui, não. A organização político-econômica brasileira não resultou da superposição de uma classe sobre uma estrutura social já constituída, superposição esta resultante da apropriação e monopolização do solo. Faltou-nos este caráter econômico fundamental do feudalismo europeu..$^{24}$

Alberto Passos, privilegiando o regime de propriedade como fundamento do modo

Werneck Sodré. Formação histórica do Brasil. 9ạ edição. Rio de Janeiro, Civilização Brasileira, 1976, p. 81-82. “Como problema fundamental, é o trabalho que vai caracterizar a exploração colonial. A coroa doava a terra. Era generosa nessa doação. Mas não doava o escravo. O escravo fazia parte do investimento inicial. Valia mais que a terra; muito mais, pois que a terra nada valia. A riqueza do senhor media-se muito mais pelo número de escravos do que pela extensão da propriedade, embora houvesse uma relação entre um e outro desses fatores. Mais preciosa para o senhor era a propriedade do escravo do que a da terra. Esta era abundante e praticamente gratuita. 0 escravo só podia ser obtido por compra, e não era barato. Ter ou não ter escravos era a questão fundamental. Aquele que não os tivesse, por mais extensas que fossem as suas terras, nada tinha. 0 prestígio do senhor media-se por uma só unidade: o escravo. A supremacia do trabalho sobre tudo 0 mais impunha-se, inexoravelmente." Idem, ibidem, p. 71.

24. Caio Prado Júnior. Evolução política do Brasil e outros estudos. 7ạ edição. São Paulo, Brasiliense, 1971, p. 18.

48 Interpretações da colônia. Leitura das contribuições de Nelson Werneck Sodré e Alberto Passos Guimarães 
de produção ultrapassa, em alguma medida, concepções que se restringem à dimensão das relações de exploração do trabalho. No entanto, sendo esse regime também realidade parcial, isolada do conjunto, o problema se repõe tão logo volta-se o olhar para a realidade concreta. Por isso a necessidade de recorrer às formas híbridas, ao feudalescravista, ao semifeudal, que tanto embaraço causaram. Werneck Sodré também não resolve o problema. Pois ao circunscrever a apreensão do modo de produção à dimensão das relações escravistas, como elemento separado da totalidade, promove uma cisão definitiva entre dois níveis da análise, relativos a dimensões mais abstratas ou mais concretas. Ou seja, trata-se de uma caracterização do modo de produção que abstrai suas determinações concretas, em favor de conceitos mais abstratos, situados na esfera das relações de produção que identificam, por fim, realidades sociais reproduzidas em diferentes épocas ou espaços, em distintos contextos históricos. O conceito estabelecido em nível estrutural, formulado em abstrato, à maneira das filosofias da história, aparece em paralelo ao nível do movimento histórico concreto, sem que se possa apreender as mediações entre os dois níveis. Assim, as duas dimensões da sociedade colonial acima citadas, relativas à acumulação primitiva e ao escravismo puro e simples, aparecem apartadas na análise sem que se possa transitar de um nível a outro, ou apreender suas determinações recíprocas. Mesmo no tratamento do feudalismo pastoril, que em nível mais imediato aparece apartado do espaço propriamente mercantil, o problema persiste. Como demonstrou Caio Prado, em nível mais profundo, os dois espaços estão articulados, e mesmo sua cisão explica-se por sua conexão estrutural, pelo sentido da colonização - a economia pastoril como resíduo da grande lavoura exportadora. Enfim, o descolamento das relações escravistas e a decorrente separação entre os dois níveis de realidade permitem o movimento geral da interpretação: compreender o movimento da sociedade colonial como parte constitutiva da dinâmica européia e, ao mesmo tempo, elaborar considerações sobre o modo de produção edificado na colônia. O movimento da sociedade colonial não poderia ser apreendido somente a partir de seus nexos sistêmicos ou a partir da dinâmica de um modo de produção especificamente colonial relativamente autônomo, pois, nas interpretações em tela, o modo de produção não seria compreendido como totalidade concreta. O problema da dupla dimensionalidade da sociedade colonial, acimia referida, torna-se mais evidente e revela-se numa espécie de justaposição sem síntese.

O problema apresenta-se paradoxal, quando se define a categoria modo de produção pelos elementos comuns, que identificam as mais variadas formações sociais. Pois então, o que poderia explicar o sentido histórico específico dessas formações, senão as 
dimensões exteriores ao próprio conceito de modo de produção? Nesse caso, o que se perde pelo ralo é o próprio materialismo. Marx considerou as formações pré-capitalistas em discurso retrospectivo, partindo do capitalismo plenamente constituído como a única forma de reprodução da vida social que se assenta sobre relações de dominação estritamente econômicas, vale dizer, única forma em que a esfera econômica adquire relativa autonomia ${ }^{25}$. Nas formas pré-capitalistas, a dominação edifica-se pelas formas de coerção extra-econômica, seja na esfera das relações familiais, jurídicas, políticas, religiosas, etc. Aqui, essas esferas extra-econômicas não funcionam como pressupostos externos de uma infra-estrutura, e menos como suas manifestações exteriores, epifenômenos. Ao contrário, compõem suas determinações estruturais, constituem seu nexo interno, em articulações concretas e, portanto, históricas. Assim, as formações pré-capitalistas apenas podem ser compreendidas no quadro de sua totalidade, com o que se pode apreender o sentido mais profundo de produção, como produção da vida. No plano das construções históricas concretas, em suas múltiplas possibilidades, as relações de produção são, como diz Eric Hobsbawm, inventadas e reinventadas, e somente em conexão com a totalidade histórica concreta, pode-se apreender o seu sentido histórico. Esse historiador atenta para o fato "das relações sociais básicas, necessariamente limitadas em número, serem 'inventadas' e 'reinventadas' pelos homens em numerosas ocasiões e de todos os modos de produção monetários (exceto, talvez, o capitalismo) serem complexos feitos de toda espécie de combinação delas"26.

25. “Marxnão discute estes aspectos da servidão nem as contradições internas da escravidão porque, nas FORMEM, não é seu propósito esboçar ‘história econômica' de qualquer das duas. Na verdade, como sempre - embora aqui de um modo mais geral - não está preocupado com a dinâmica interna dos sistemas pré-capitalistas, exceto na medida em que explicam as condições prévias do capitalismo". Eric Hobsbawm: "Introdução". In: Karl Marx. Formações econômicas pré-capitalistas, trad. João Maia. za edição. Rio de Janeiro, Paz e Terra, 1977, p. 43.

26. Idem, ibidem, p. 58-59.

50 Interpretações da colônia. Leitura das contribuições de Nelson Werneck Sodré e Alberto Passos Guimarães 